LA-UR-99- - 88

Title:

ENVIRONMENTAL MANAGEMENT POLICY

ANALYSIS USING COMPLEX SYSTEM

SIMULATION

Author:

Edward M. Van Eeckhout, TSA-4

Douglas J. Roberts, TSA-12

Williams R. Oakes, Jr., X-CM

Andrew Shieh, TSA-4

R. Wayne Hardie, TSA-4

Paul A. Pope, TSA-4

MASTER

Submitted to:

DOE Office of Scientific and Technical Information (OSTI)

DISTAHUUTON OF THIS DOCUMENT IS URLMMTED
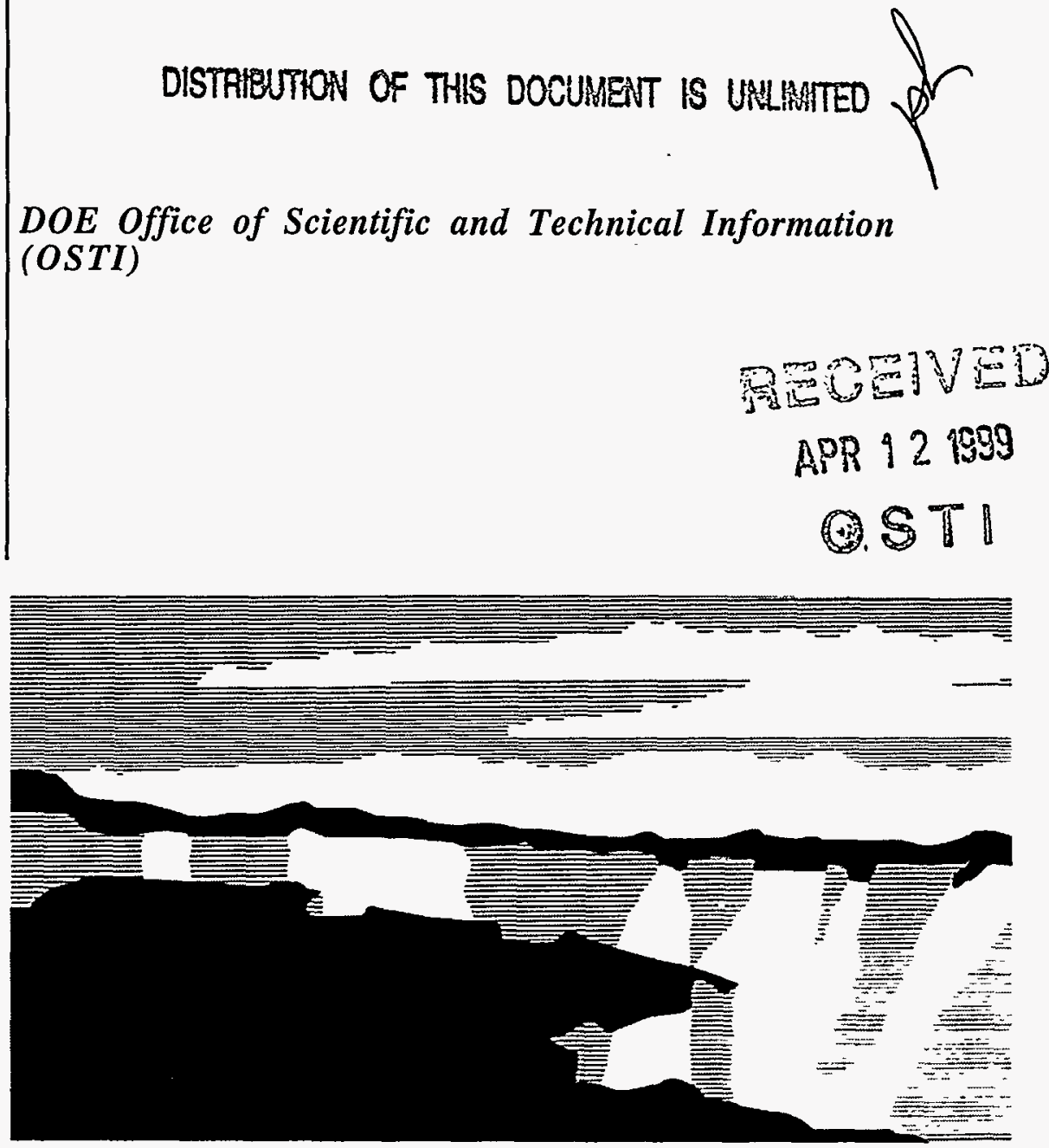

NATIONAL LABORATORY

Los Alamos National Laboratory, an affirmative action/equal opportunity employer, is operated by the University of California for the U.S. Department of Energy under contract W-7405-ENG-36. By acceptance of this article, the publisher recognizes that the U.S. Government retains a nonexclusive, royalty-iree license to publish or reproduce the published form of this contribution, or to allow others to do so, for U.S. Government purposes. The Los Alamos National Laboratory requests that the publisher identify this article as work performed under the auspices of the U.S. Department of Energy. Los Alamos National Laboratory strongly supports academic freedom and a researcher's right to publish; therefore, the Laboratory as an institution does not endorse the viewpoint of a publication or guarantee its technical correctness. 


\section{DISCLAMMER}

This report was prepared as an account of work sponsored by an agency of the United States Government. Neither the United States Government nor any agency thereof, nor any of their employees, makes any warranty, express or implied, or assumes any legal liability or responsibility for the accuracy, completeness, or usefulness of any information, apparatus, product, or process diselosed, or represents that its use would not infringe privately owned rights. Reference berein to any specifie commercial product, process, or service by trade name, traderastk, manufacturer, or otherwise does not necessarily constitute or imply its endorsement. recom. mendation, or favoring by the United States Goverament or any ageacy thereof. The views and opinions of authors expressed herein do not necasarily state or reflect those of the United States Government or any agency thereof. 


\section{DISCLAIMER}

Portions of this document may be illegible in electronic image products. Images are produced from the best available original document. 


\title{
Environmental Management Policy Analysis - using - Complex System Simulation
}

\author{
Ed Van Eeckhout*, Doug Roberts, Rob Oakes, Andrew Shieh, Wayne Hardie, Paul Pope
}

\begin{abstract}
The two primary modules of Envirosim (the model of Los Alamos TA-55 and the WIPP transport/storage model) have been combined into one application, with the simulated waste generated by TA-55 operations being fed to storage, packaging, and transport simulation entities. Three simulation scenarios were executed which demonstrate the usefulness of Envirosim as a policy analysis tool for use in planning shipments to WIPP. A graphical user interface (GUI) has been implemented using IDL (Interactive Data Language) which allows the analyst to easily view simulation results. While IDL is not necessarily the graphics interface that would be selected for a production version of Envirosim, it does provide some powerful data manipulation capabilities, and it runs on a variety of platforms.
\end{abstract}

\section{Background and Research Objectives}

Environmental clean-up and management is an extremely complex arena in which to manage policy. The interaction of the public, private industry, federal and state policies, regulations, technology, and natural phenomena creates a system whose goals and activities evolve rapidly. This type of system, combining technology with human behavior, is impossible to manage properly using traditional policy analysis tools. A new method is needed - one that relies on a fundamentally different approach to policy analysis and assessment.

One of the most intractable aspects of environmental management is the fact that the measures we use to gage our success are changeable. It seems that just when we think we have a pollution problem solved, new regulations are promulgated to redefine the acceptable level of the pollutant. This creates severe tensions between the public and the site operators, and is also very costly to our economy.

The complicating factor for environmental management is that, although the initial goals for the system may originate with the public, the final goals emerge from the interactions of all the elements of the system. That is, as science improves the level of clean-up possible, the goals for the clean up may change. For example, the definition of "clean" water (or air) is largely determined by the sensitivity of our detection methods. As our sensors improve with advances in science, the public sometimes expects the allowed impurities to decline from parts per million to parts per billion and beyond.

Of course, to manage this system during times of constrained or declining budgets, technology development is critical - it is the driver that determines productivity improvement over time. But one must realize that the system is a totally interlinked, interdependent system with human actors and decisions leading to previously unexpected results (this is an example of "emergent behavior").

The specific waste and technology characteristics are relatively fixed and are easiest to understand; they provide the initial boundary conditions. Policy, goals, and technology choice are all mutually determined within the system, and cannot be pre-determined. The institutional relations among the public, business, regulators, technology developers, and politicians evolve and derive the system outcome. 
Beginning during World War II and continuing through the Cold War, the United States developed a nuclear weapons production complex involving more that 130 sites and facilities in over 30 states and territories (see figure below). Because of the priority on weapons production among other reasons, the handling of radioactive and hazardous waste resulted in environmental contamination and the temporary storage of enormous quantities of dangerous materials. The combined effects of society's increased environmental expectations along with the decreasing necessity for weapons production has resulted in a strong focus upon dealing with the legacy of environmental hazards and concerns, the "Cold War Mortgage."

In 1989 the DOE established the Office of Environmental Management (DOE/EM) to manage what would become one of the largest environmental management programs in the world. The primary goal of this program is to reduce health and safety risks from radioactive waste and contamination resulting from the production, development and testing of nuclear weapons, and to return DOEcontrolled land to the public to the maximum extent practicable. The Environmental Management program will be complete when the health and safety risks from legacy waste, materials, sites, and facilities have been minimized.

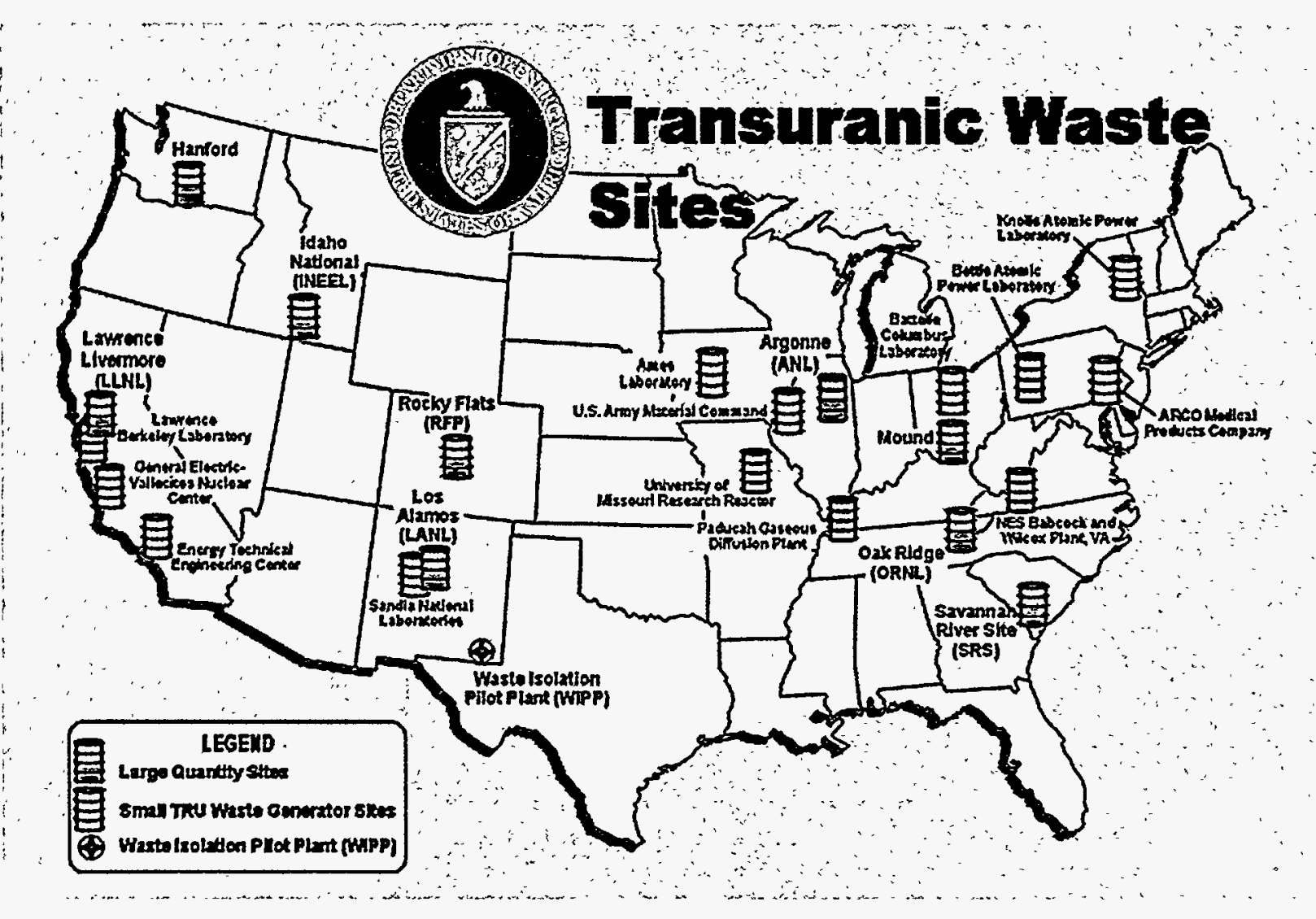




\section{Importance to LANL's Science and Technology Base and National R \& D Needs}

As stated in the DOE's 1995 BEMR, "The Department of Energy's Office of Environmental Management, established in 1989, manages the largest environmental stewardship program in the world." In order to optimize their stewardship program, they must be able to make decisions concerning budget, scheduling, and risk while having the best possible information relative to the decisions. The intent of the current analysis and simulation project is to improve the quality and timelines of required decisional information.

\section{Scientific Approach and Accomplishments}

For the past several years, Los Alamos has been developing a fundamentally different approach to policy analysis and assessment using a new and advanced simulation approach. The approach is amenable to very large-scale, complex systems (e.g., transportation, environment, etc.) that are characterized by thousands, or even millions, of interactions among the components of the system. Moreover, it also lends itself to analyzing systems where human decision making is integral to the choice and implementation of component interactions in the system.

Traditional simulation systems invariably trend towards a very deep, hi-fidelity characterization of the system being assessed. Often, as is the case with environmental restoration, the characterization, in and of itself, is an immensely time consuming, very expensive activity that is based on the premise that in order to effect good policy and use limited funds appropriately, we need to simulate at a level of minute, sometimes excruciating detail of system dynamics in order to understand overall system behavior. The advent of high performance supercomputing, increasingly powerful database management systems, and an ever present desire to get things "exactly right" scientifically, in many instances contributes to the ill-advised development of a computational system that is so expensive and so inflexible that it never can be effectively used.

In contrast, the simulation approaches that we have been developing are based on very different assumptions. First, we assume that simplicity of the computational system is a goal; that is, we assume that there is a level of complexity in the simulated system components, which if you go beyond, the understanding of policy issues concerning the system does not improve and often gets worse. This leads us to develop the simplest component representation we can get by with while still fully addressing the policy/budget considerations at hand. Second, we construct these components so that they are capable of self-organizing and evolving in order to achieve the overall goals of senior decision-makers. In essence, in traditional simulation approaches, we put policy and plans, developed by humans, into the simulation, and get from the simulation results on how effective they are. In our new approach (see figure below), we cause the simulation to produce alternative policies and plans to help us achieve some overall objectives, and let the computer search for the most powerful set of procedures and processes within budget constraints to achieve these objectives. 




Functional Representation of the Los Alamos-to-WIPP Waste Transport Process

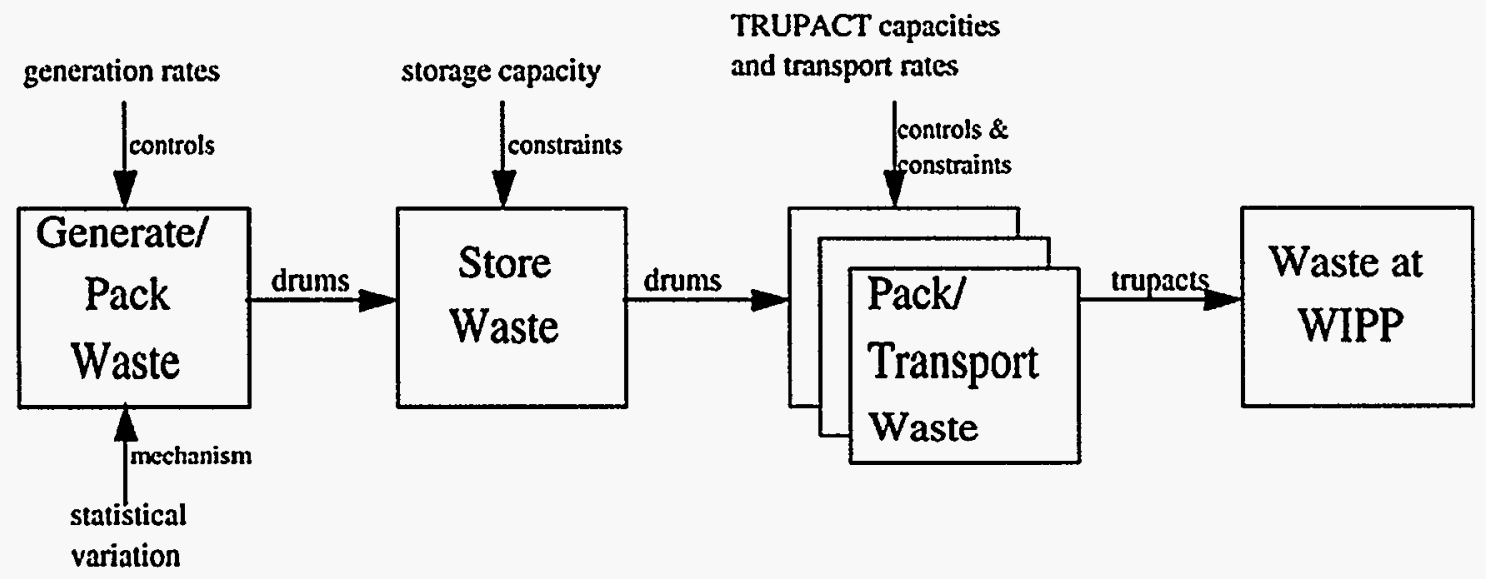

Simulation science is undergoing rapid changes which allow addressing large-scale, nonlinear, complex socio-economic problems. It can now provide unique ways to analyze and assess largescale systems that are dominated by the interactions of numerous intelligent agents yielding highly complex, nonlinear behavior on a macroscopic scale. 


\section{Example Analysis Scenarios}

Three analysis scenarios were selected to illustrate how ENVIROSIM might be used by a customer like the DOE Carlsbad Area Office to help manage WIPP operations.

1. Two simulations were run to illustrate the effect of changing TruPact loading logic on the number of drums shipped to WIPP over a 10-year period. Since TruPact loading logic is multiply constrained on Pu limits, volume limits, radiation limits, etc., changes in loading logic can affect TruPact loading efficiency. The interface window for this scenario contains two plots. The graph on the left shows the plutonium $(\mathrm{Kg})$ shipped to WIPP for the each case, and the graph on the right is the difference plot of the two simulation runs.

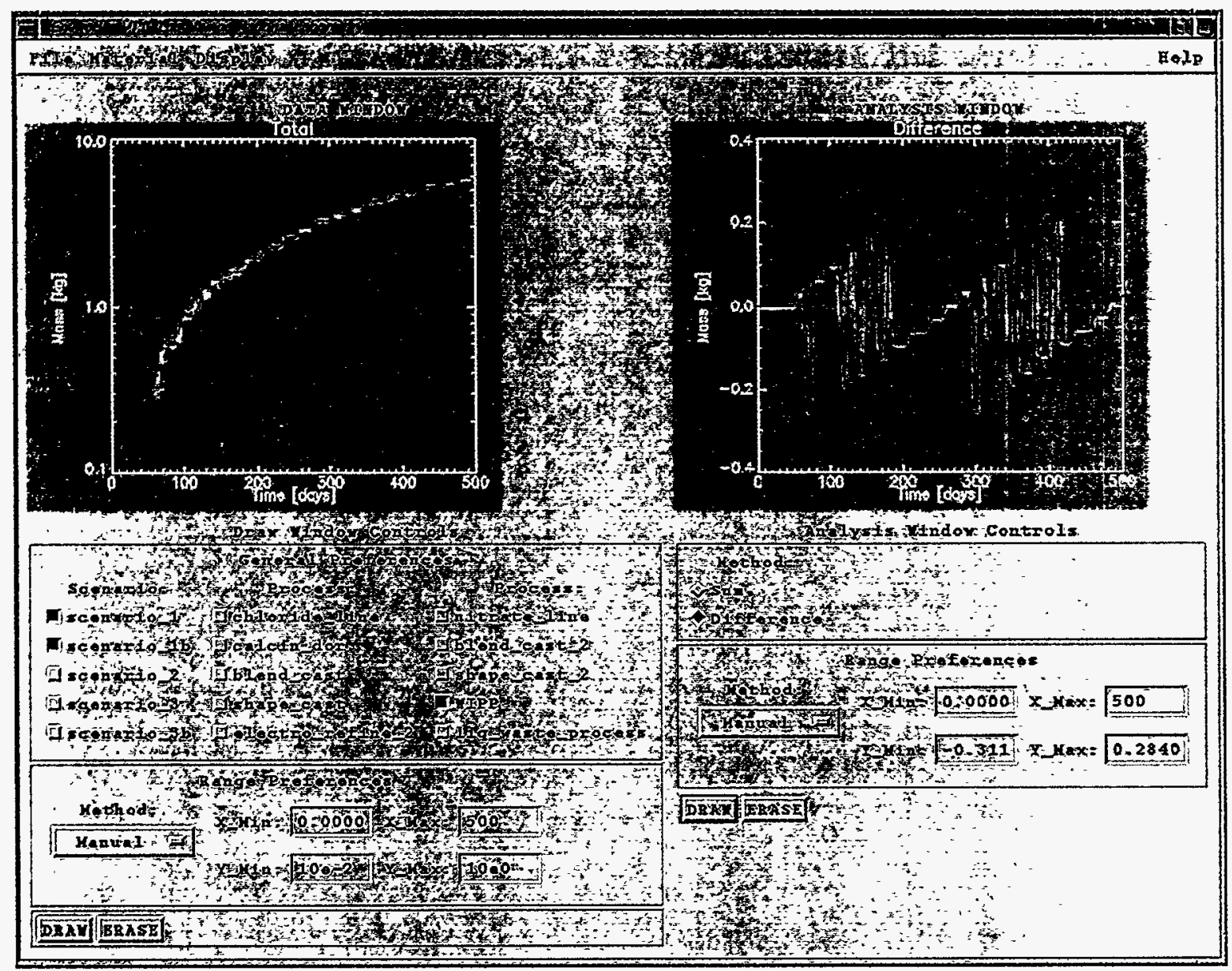


2. Shipments to WIPP were halted after 4 years, providing the analyst with the capability to predict how long TA-55 could continue to operate before internal storage limitations forced a shutdown. This scenario was of interest because it shows how the model can provide analysts with the ability to study system-wide infrastructure changes; predicting the impact on producers of waste as well as the impact on WIPP. The plots for this run show a sequenced shutdown of processing lines inside TA-55 as internal storage constraints are reached.

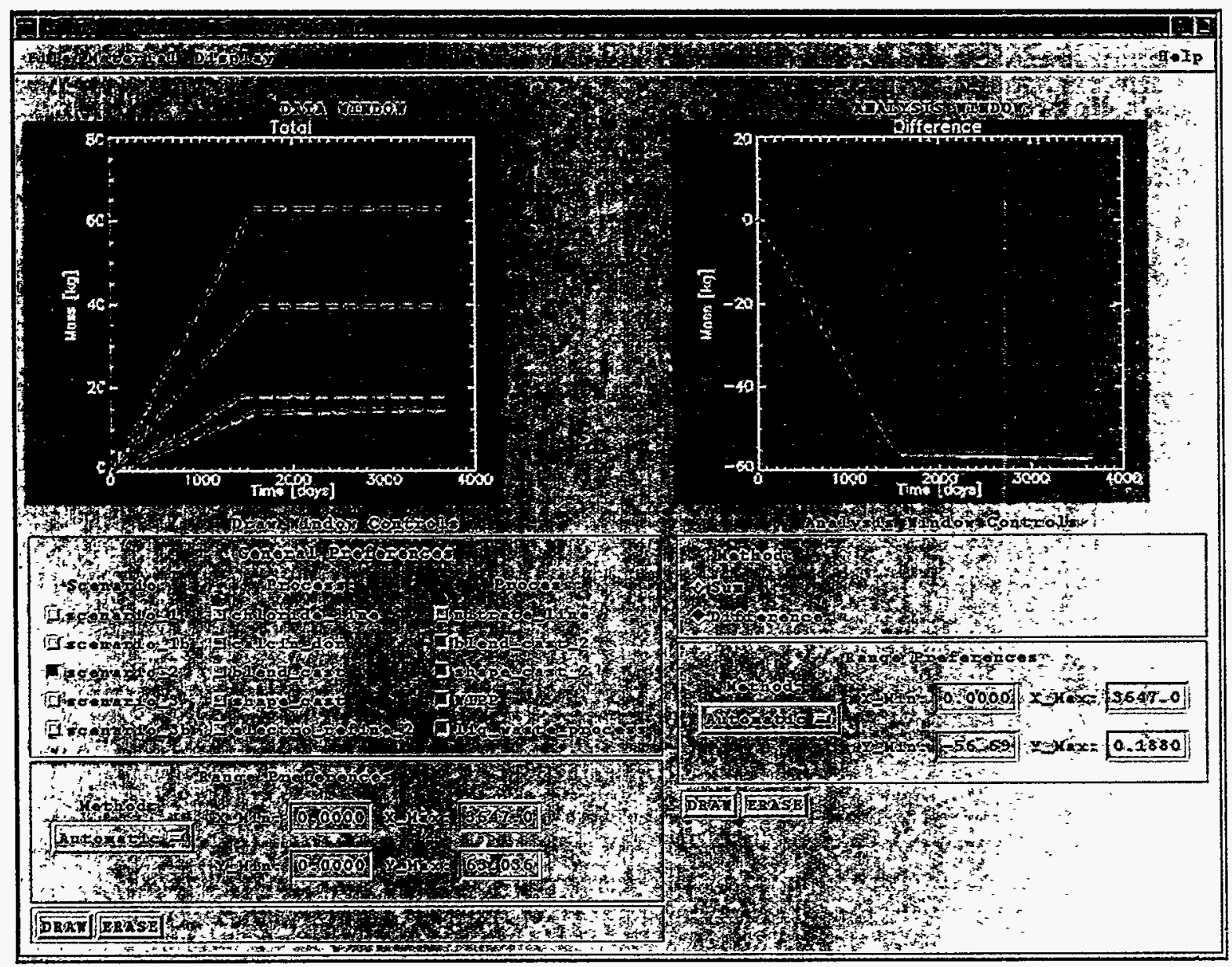


3. Two simulations were run to view the effect of change from a "base" case to one where a processing efficiency is changed. This scenario was presented to illustrate how the model could be used to simulate the impact on the system of technology changes. The interface window shown below was used to observe the effect of the efficiency change on both product and waste generation. The plots for this scenario show the impact of the processing efficiency change on several of the processing lines downstream of where the efficiency change was implemented at TA-55.

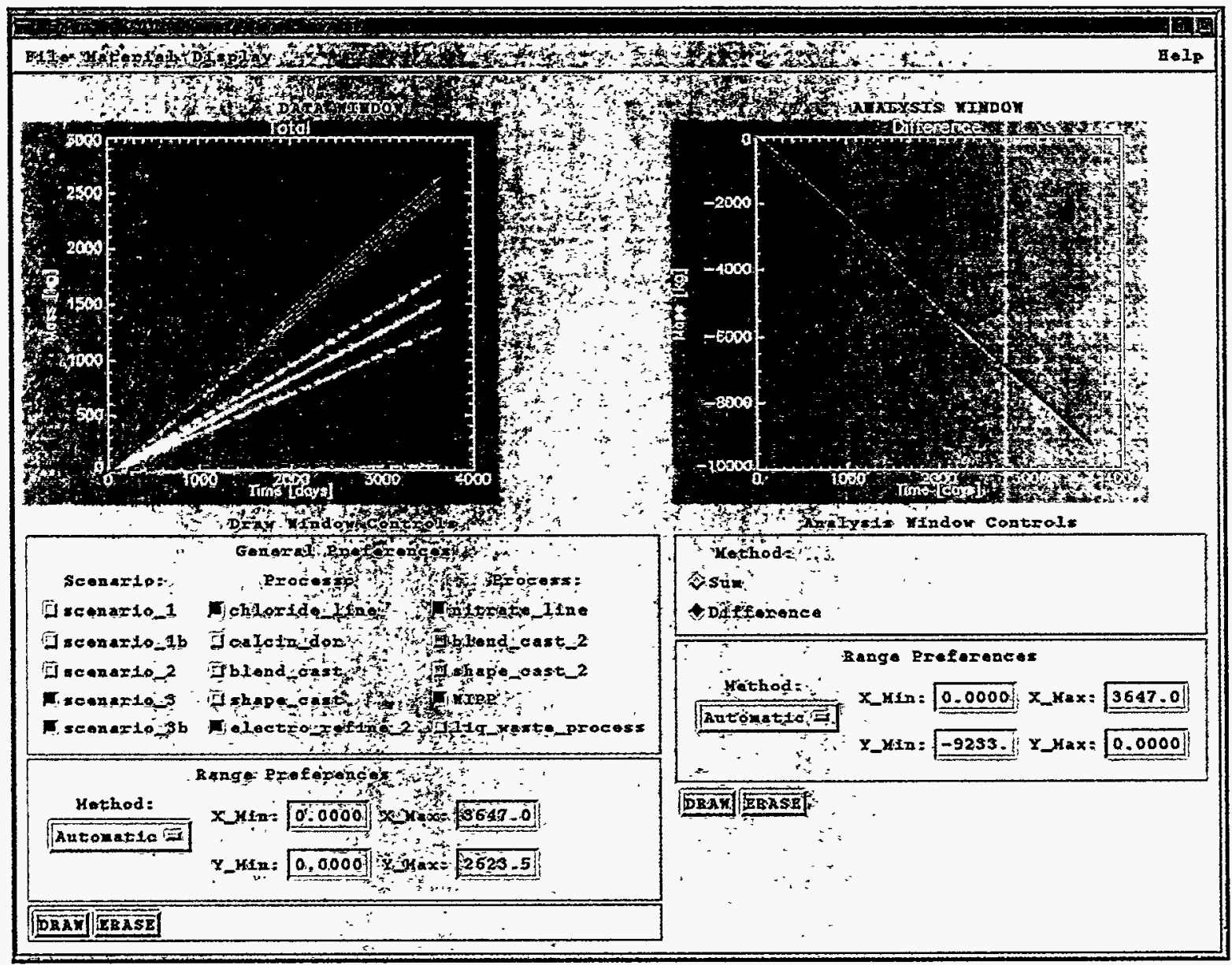

